\title{
Radar-Derived Quantitative Precipitation Estimation Based on Precipitation Classification
}

\author{
Lili Yang, ${ }^{1,2}$ Yi Yang, ${ }^{1}$ Peng Liu, ${ }^{1}$ and Lina Wang ${ }^{2}$ \\ ${ }^{1}$ Key Laboratory for Semi-Arid Climate Change of the Ministry of Education, Key Laboratory of Arid Climatic Changing and \\ Reducing Disaster of Gansu Province, College of Atmospheric Sciences, Lanzhou University, Lanzhou 730000, China \\ ${ }^{2}$ Gansu Province Environmental Monitoring Center, Lanzhou 730020, China
}

Correspondence should be addressed to Yi Yang; yangyi@lzu.edu.cn

Received 30 June 2016; Accepted 13 October 2016

Academic Editor: Zhe Li

Copyright (C) 2016 Lili Yang et al. This is an open access article distributed under the Creative Commons Attribution License, which permits unrestricted use, distribution, and reproduction in any medium, provided the original work is properly cited.

\begin{abstract}
A method for improving radar-derived quantitative precipitation estimation is proposed. Tropical vertical profiles of reflectivity (VPRs) are first determined from multiple VPRs. Upon identifying a tropical VPR, the event can be further classified as either tropical-stratiform or tropical-convective rainfall by a fuzzy logic (FL) algorithm. Based on the precipitation-type fields, the reflectivity values are converted into rainfall rate using a $Z-R$ relationship. In order to evaluate the performance of this rainfall classification scheme, three experiments were conducted using three months of data and two study cases. In Experiment I, the Weather Surveillance Radar-1988 Doppler (WSR-88D) default $Z-R$ relationship was applied. In Experiment II, the precipitation regime was separated into convective and stratiform rainfall using the FL algorithm, and corresponding $Z$ - $R$ relationships were used. In Experiment III, the precipitation regime was separated into convective, stratiform, and tropical rainfall, and the corresponding $Z-R$ relationships were applied. The results show that the rainfall rates obtained from all three experiments match closely with the gauge observations, although Experiment II could solve the underestimation, when compared to Experiment I. Experiment III significantly reduced this underestimation and generated the most accurate radar estimates of rain rate among the three experiments.
\end{abstract}

\section{Introduction}

Owing to its significant impacts on human activities, precipitation is one of the most important factors in meteorological analysis; accordingly, its study has attracted considerable attention. Quantitative precipitation estimation (QPE) plays a very important role in generating warnings of meteorological, hydrological, and geological disasters. The accuracy of numerical weather predictions can be significantly improved when the precipitation rate is assimilated into the weather prediction models $[1,2]$. Currently, precipitation rate data is obtained primarily from rain gauge networks, which can provide real-time rainfall estimates. However, the spatial distribution of rain gauges is sparse in remote regions, particularly in mountainous areas, which can result in insufficient spatial resolution for accurate mapping of the rainfall patterns. Consequently, obtaining QPE products with high spatial and temporal resolution is currently one of the main tasks in conducting hydrometeorological studies $[3,4]$.
Weather radars, in particular, can provide precipitation estimates with high spatial and temporal resolution over a large area [5]. Radar reflectivity, $Z\left(\mathrm{~mm}^{6} / \mathrm{m}^{3}\right)$, is related to rainfall rate, $R(\mathrm{~mm} / \mathrm{h})$, through a variable power law relationship $(Z$ $R$ relationship), which can be used to obtain QPE products.

Numerous $Z-R$ relationships based on raindrop size distribution observations have been proposed [6-8]. Z-R relationships of the form $Z=A R^{B}$ can be derived from pairs of $Z$ and $R$ observations, assuming that sufficient corresponding paired $Z-R$ data samples are available. The default WSR-88D $Z$ - $R$ relationship, $Z=300 R^{1.4}$ [9-11], was derived based on summer convective events in Florida, USA. However, this default $Z-R$ relationship cannot fully address the complicated characteristics of rain in, for example, China [12-14]. It is known that different types of precipitation correspond to different raindrop size distributions (DSDs), and precipitation types can also be classified based on the formation mechanism, duration, and internal structure. The precipitation regime can therefore be divided into different rainfall types. 
Convective rainfall systems are associated with strong vertical velocity fields, small areal coverage, and high rainfall intensities, and an echo that can be extended to a relatively high altitude and with a high center of mass. Conversely, stratiform rainfall systems have relatively weak vertical velocity fields, great horizontal homogeneity, and low rainfall intensity. Although the intensity of stratiform rainfall is much weaker than that in adjacent convective cells, stratiform rain typically covers a larger area and always contributes with a significant portion $(40-50 \%)$ of the total rainfall, even in convectivedominant systems [15]. Tropical rain systems generally occur in lower altitudes and very humid air, with condensation occurring continuously throughout the air descent. The main feature of tropical rain systems is that their reflectivity increases monotonically as height decreases, yielding a maximum reflectivity at the lowest levels of the vertical profile of reflectivity (VPR), resulting in considerable error when conducting precipitation estimation using the default $Z-R$ relationship of WSR-88D. Moreover, multiple types of precipitation may coexist within a wide range of rainfall events.

Radar research scientists worldwide have undertaken extensive studies to improve the accuracy of radar QPE [1623]. Typically, precipitation is first classified into various types, and corresponding multiple $Z$ - $R$ relationships are then used $[19,24-26]$. Precipitation can generally be classified into either convective or stratiform regimes, which has been a particular focus of many studies [27-29]. Such basic classifications typically adopt a fixed threshold or set of boundary conditions for rainfall recognition. However, these methods are known to be sensitive to the used threshold values and because there is a considerable overlap between stratiform and convective regimes in many respects, using fixed boundary conditions or thresholds often leads to false positives. Moreover, it is often difficult to directly identify the boundary between stratiform and convective regimes [30]. Yang et al. [30] used the reference values of Steiner et al. [29] to derive a statistical relationship between four characteristic parameters and two rain types, in order to develop the probability distribution of convective and stratiform rainfall based on a fuzzylogic (FL) algorithm, which was able to improve the accuracy of QPE [31]. Despite efforts such as these, many techniques can still underestimate rainfall to some extent. Based on the stratiform and convective precipitation classification, many researchers have suggested focusing on tropical rain as an avenue to mitigate the underestimation of QPE, and some studies have been able to reduce QPE underestimation by employing an automated radar technique to identify tropical precipitation, in order to divide precipitation into tropical rain and stratiform and convective types [32,33]. Qi et al. [34] converted reflectivity into precipitation utilizing the tropical rain $Z-R$ relationship instead of the default WSR-88D $Z-R$ relationship, which improved the accuracy to some extent. Similarly, Zhang et al. [35] improved the accuracy of radarderived QPE by using an automatic identification method to identify tropical, stratiform, and convective precipitation types based on radar observations and model outputs. They then applied various $Z-R$ relationships in order to convert reflectivity into rain rates, based on precipitation types. The results showed that their method improved the accuracy of radar-derived QPE.

In this study, precipitation is first divided into stratiform and convective precipitation types using the FL algorithms proposed by Yang et al. [30], and then tropical rain is identified based on the VPR characteristics [36, 37], as discussed by $\mathrm{Xu}$ et al. [33]. Tropical rainfall is further divided into tropicalstratiform and tropical-convective rainfall, and the respective adaptive $Z-R$ relationships are then applied for QPE. A three-month dataset is used to compare the newly proposed tropical rain identification scheme with the results obtained with the default WSR-88D $Z-R$ relationship and a convective/stratiform rain identification scheme. Section 2 describes the precipitation classification method and the corresponding $Z-R$ relationships and discusses the benefits of precipitation classification. Section 3 illustrates the evaluation results of using long-term datasets using descriptive statistics. Two case studies are also provided in Section 4 to evaluate the performance of the proposed precipitation classification method. Finally, Section 5 presents the main results of the study.

\section{Algorithm Description}

Underestimation of rainfall can occur when precipitation is divided into general stratiform and convective types. This study aims to improve the accuracy of radar QPE by building upon the convective, stratiform, and tropical precipitation technique described by $\mathrm{Xu}$ et al. [33]. The proposed method uses volume scan reflectivity data from a Doppler radar to recognize tropical VPRs, by first dividing rain data into stratiform and convective precipitation (using an FL algorithm) and then classifying tropical rain events as stratiform, convective, or tropical precipitation. Figure 1 shows a flow chart illustrating this process of precipitation classification.

2.1. Identification of Tropical VPRs. This study uses VPRs to identify the potential presence of tropical rain. As a first step, volume scan reflectivity data from Doppler radar are simply classified into assumed stratiform or convective types, based on the vertically integrated liquid (VIL) water content. In particular, the data are classified as belonging to the stratiform type when the VIL value is below $6.5 \mathrm{~kg} / \mathrm{m}^{2}$ [38]; otherwise, they are classified as convective. Stratiform reflectivity observations larger than $10 \mathrm{dBZ}$ from all tilts in an annular region between two predefined ranges, $r_{1}$ and $r_{2}$ (with the empirical values of 20 and $80 \mathrm{~km}$, resp.), are used to obtain an averaged VPR [39]. The number of data samples within a $20-\mathrm{km}$ radius of the radar is limited, owing to a terrain clearance rule incorporated into a quality control (QC) scheme [40], whereby any radar bin whose bottom is within $50 \mathrm{~m}$ of the ground is removed. Furthermore, the region of interest has to be far enough from the radar receiver, to avoid the cone of silence in the receiver's immediate vicinity. The accuracy of precipitation classification is also limited by the decrease in vertical resolution beyond an 80 $\mathrm{km}$ radius.

The second step combines the output of the first step with the method of bright band identification proposed by Zhang 


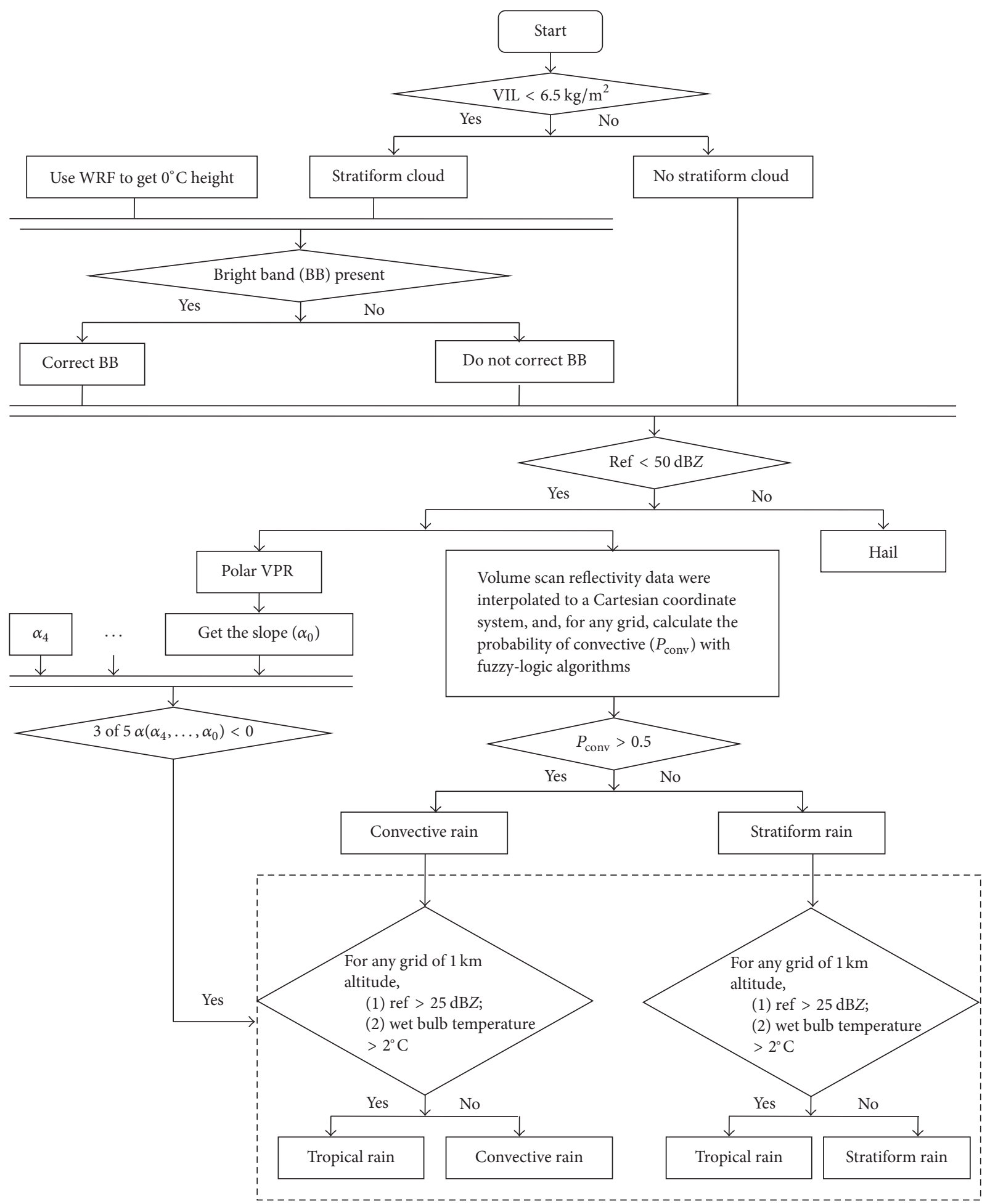

FIGURE 1: Flow chart of the precipitation classification method devised in this study.

et al. [39], to determine whether a bright band is present. The specific method adopted for this step can be summarized as follows:

(1) The local maximum reflectivity $\left(Z_{\text {peak }}\right)$ and its height $\left(h_{\text {peak }}\right)$ in the VPR are found. The search for the local maximum in the VPR starts at $500 \mathrm{~m}$ above the $0^{\circ} \mathrm{C}$ isotherm altitude $\left(h_{-} 0^{\circ} \mathrm{C}\right)$ obtained from the Weather Research and Forecasting (WRF) model and continues downward. A 500-m cushion is used to account for uncertainties in the model's $0^{\circ} \mathrm{C}$ height. 
(2) Once the local maximum is found, the height $h_{\text {top }}$ ( $\left.h_{\text {bottom }}\right)$ above (below) the maximum level at which reflectivity decreases monotonically by a given percentage (default $=10 \%$ ) [39] of the maximum reflectivity (in $\mathrm{dBZ}$ ) is determined, along with its corresponding reflectivity $Z_{\text {top }}\left(Z_{\text {bottom }}\right)$.

(3) If the following three criteria are met, a bright band is considered to exist:

$$
\begin{aligned}
h_{\text {top }}-h_{\text {bottom }} & \leq D_{0}, \\
h_{\text {top }}-h_{\text {peak }} & \leq D_{1}, \\
h_{\text {peak }}-h_{\text {bottom }} & \leq D_{1} .
\end{aligned}
$$

The parameters $D_{0}$ and $D_{1}$ are assumed to be dependent on both the vertical resolution of the reflectivity observations and the radar scan strategy. Here, $D_{0}$ and $D_{1}$ are set to 1.5 and $1 \mathrm{~km}$, respectively.

(4) If a bright band exists, its top $\left(\mathrm{BB}_{t}\right)$ and bottom $\left(\mathrm{BB}_{b}\right)$ heights are defined as follows:

$$
\begin{aligned}
& \mathrm{BB}_{t}= \begin{cases}h_{\text {top }}, & h_{\text {top }}-h_{\text {peak }} \leq D_{t}, \\
h_{\text {peak }}+D_{t}, & h_{\text {top }}-h_{\text {peak }}>D_{t},\end{cases} \\
& \mathrm{BB}_{b}= \begin{cases}h_{\text {bottom }}, & h_{\text {peak }}-h_{\text {bottom }} \leq D_{b}, \\
h_{\text {peak }}-D_{b}, & h_{\text {peak }}-h_{\text {bottom }}>D_{b} .\end{cases}
\end{aligned}
$$

Here, $D_{t}$ and $D_{b}$ serve as top and bottom caps of the bright band (BB), with default values of 500 and $700 \mathrm{~m}$, respectively [39].

To avoid excessive corrections of the bright band, the height of the local maximum reflectivity is searched again if the minimum reflectivity is lower than a preset threshold (default $=28 \mathrm{dBZ}$ ). This height is defined as the lowest height at which the reflectivity is larger than or equal to the threshold [38]. This parameter can sometimes lead to insufficient or excessive bright band correction, an issue that will be solved in the future using observations from a dual-polarization radar [41].

The third step involves the correction of any existing bright bands [42]. If the values of $\mathrm{BB}_{t} \mathrm{BB}_{b}$ and their corresponding reflectivities $\left(Z_{\mathrm{B} t}\right.$ and $Z_{\mathrm{B} b}$, resp.) are valid, $\mathrm{BB}_{b}<$ $h_{\text {peak }}$, and $\mathrm{BB}_{t}>h_{\text {peak }}$, and then the slope $(S)$ of reflectivity between $\mathrm{BB}_{t}$ and $\mathrm{BB}_{b}$ is calculated as follows:

$$
S=\frac{\left(Z_{\mathrm{B} t}-Z_{\mathrm{B} b}\right)}{\left(\mathrm{BB}_{t}-\mathrm{BB}_{b}\right)} .
$$

If the reflectivity height $h_{i}$ is located between $\mathrm{BB}_{t}$ and $\mathrm{BB}_{b}$, the reflectivity is reassigned as

$$
Z_{i}=Z_{\mathrm{B} t}-S \times\left(\mathrm{BB}_{t}-h_{i}\right) .
$$

If $\mathrm{BB}_{t}$ does not exist, the value of $\mathrm{BB}_{b}$ is valid, and $\mathrm{BB}_{b}<$ $h_{\text {peak }}$, and the reflectivities located above $\mathrm{BB}_{b}$ (with value larger than $Z_{\mathrm{B} b}$ ) are reassigned to $Z_{\mathrm{B} b}$.
The fourth step, which involves reflectivity observations from all tilts in an annular region between 20 and $80 \mathrm{~km}$, involves recalculation of the average stratiform VPR after bright band correction.

The fifth step involves determining whether a tropical VPR has been captured. Following Xu et al. [33], the identification (or diagnosis) of tropical VPR is made with a leastsquares fit from the bottom of the bright band to the bottom of the VPR, in cases where a bright band exists; otherwise, the fit is made from $h_{-} 0^{\circ} \mathrm{C}$ to the bottom of the VPR. The slope $(\alpha)$ of the VPR is then calculated. The resulting VPR is considered as tropical if three out of five values of $\alpha$ (for the present and the four previous moments) are lower than or equal to 0 ; otherwise, it is regarded as a nontropical VPR.

2.2. Convective and Stratiform Rainfall Classification. To improve the accuracy of radar QPE, this study adopted the FL algorithm developed by Yang et al. [30] to classify convective and stratiform rainfall. Brief details of the FL algorithm are given below.

First, the volume scan reflectivity data from the Doppler radar are interpolated to a Cartesian coordinate system with the same latitude and longitude range $\left(0.01^{\circ}\right)$ of the original data. Four features, denoted as $F_{1}-F_{4}$, are calculated based on the reflectivity data. These features are, respectively, (a) the reflectivity at $2 \mathrm{~km}$, (b) the reflectivity standard deviation in the horizontal direction, (c) the product of the radar top height and the reflectivity value at $2 \mathrm{~km}$, and (d) the vertically integrated liquid water content [30].

As a second step, membership functions are used to determine the degree to which each feature belongs to each rain type, using a fuzzification process. Linear functions are used as membership functions for convection:

$$
\mu_{k, C}(x, a, b)= \begin{cases}0, & x \leq a, \\ \frac{(x-a)}{(b-a)}, & a<x<b, \\ 1, & x \geq b, \\ & (k=1,2, \ldots, N)\end{cases}
$$

and stratification:

$$
\mu_{k, S}(x, a, b)= \begin{cases}1, & x \leq a, \\ \frac{(b-x)}{(b-a)}, & a<x<b, \\ 0, & x \geq b,\end{cases}
$$

$$
(k=1,2, \ldots, N)
$$

where $N$ is the input feature parameter, subscript $k$ is set to 1 , 2,3 , or $4, C$ and $S$ identify the convective and stratiform cases, respectively, $x$ is the feature value, $a$ is the left breaking point, and $b$ is the right breaking point. Different feature parameters are assigned different breaking points. For $F_{1}$, the parameters are set to $a=20 \mathrm{dBZ}$ and $b=45 \mathrm{dBZ}$; for $F_{2}$, they are $a=$ $1 \mathrm{dBZ}$ and $b=14 \mathrm{dBZ}$; for $F_{3}$, they are $a=100 \mathrm{~km} \cdot \mathrm{dBZ}$ and 
$b=500 \mathrm{~km} \cdot \mathrm{dBZ}$; and, for $F_{4}$, they are $a=0.5 \mathrm{~kg} / \mathrm{km}^{2}$ and $b=$ $5.0 \mathrm{~kg} / \mathrm{km}^{2}$ [30]. From (5) and (6), it is clear that

$$
\mu_{k, S}(x, a, b)=1-\mu_{k, C}(x, a, b) .
$$

Third, the weighted average values of the measurement belonging to each specific class are obtained as follows:

$$
P_{e}=\frac{\left(\sum_{k=1}^{N} W_{k} \cdot P_{k, e}\right)}{\left(\sum_{k=1}^{N} W_{k}\right)},
$$

where $P_{k, e}=\mu_{k, \varepsilon}\left(X_{k}\right), e$ identifies the convective or stratiform case, $W_{k}$ is the weighting factor (with equal weighting assigned in this study for simplicity), $N$ is the number of input feature parameters, and $P_{c}$ and $P_{s}$ indicate the weighted average values of the convective and stratiform classes, respectively. As the sum of $P_{c}$ and $P_{s}$ is 1 , the value of $P_{c}$ can be used to express classifications for convection in a probabilistic manner. Grid points for which $P_{c} \geq 0.5$ are classified as convective rainfall; all other grid points are classified as stratiform rainfall.

2.3. Identification of Tropical Rainfall Regions. To improve the accuracy of the radar QPE, tropical rainfall is considered to be present if tropical VPR is present and the grid at $1 \mathrm{~km}$ altitude meets the following two criteria [33]: (1) the reflectivity is greater than $25 \mathrm{dBZ}$ and (2) the surface wet bulb temperature is greater than $2^{\circ} \mathrm{C}$. The surface wet bulb temperature is calculated as follows:

$$
\begin{aligned}
& E=6.11 \times 10^{7.5 \times T_{d c} /\left(237.7+T_{d c}\right)} \\
& W_{B c} \\
& =\frac{\left(0.00066 \times P \times T_{c}+4098 \times E / T_{d c} \times\left(237.7+T_{d c}\right)^{2}\right)}{\left(0.00066 \times P+4089 \times E /\left(237.7+T_{d c}\right)^{2}\right)},
\end{aligned}
$$

where $T_{d c}$ is the dew point temperature (in ${ }^{\circ} \mathrm{C}$ ), $E$ is the vapor pressure from dew point (in mb), $W_{B C}$ is the surface wet bulb temperature (in ${ }^{\circ} \mathrm{C}$ ), $P$ is the pressure (in $\mathrm{mb}$ ), and $T_{c}$ is the air temperature (in ${ }^{\circ} \mathrm{C}$ ). The above parameters are simulated using the WRF model or from other data.

In this way, stratiform rainfall is further divided into stratiform and tropical-stratiform rainfall, and convective rainfall is further divided into convective and tropicalconvective rainfall.

2.4. Radar QPE Calculation. Three sets of experiments were conducted to test the proposed method. In Experiment I, only the WSR-88D default $Z-R$ relationship $\left(Z=300 R^{1.4}\right)$ was used. In Experiment II, as the rain type is identified by a FL algorithm, the corresponding $Z-R$ relationships were applied to the rain rate calculation at each grid point. For each grid point, the relationship $Z=300 R^{1.4}$ was applied for the convective rainfall calculation if $P_{c} \geq 0.5$. Otherwise, the relationship $Z=200 R^{1.6}$ [6] was applied, for stratiform rainfall calculation. In Experiment III, stratiform and convective rainfall in tropical rainfall events were further divided into stratiform and tropical-stratiform rainfall and convective and tropical-convective rainfall, respectively. The relationships were the same as those used in Experiment II, except that the tropical rainfall relationship $Z=30.7 R^{1.66}$ was adopted (Yadong Wang, personal communication). In an attempt to exclude the impact of nonprecipitation echoes and hail, quality control was conducted prior to precipitation classification. Additionally, reflectivity at $1 \mathrm{~km}$ was used to reduce the errors caused by spatial inconsistencies and the effects of bright band measurements not yet properly revised.

2.5. Performance Evaluation. The mean deviation error (BIAS), relative absolute error (RAE) rate, and root mean square error (RMSE) are selected as statistical indicators for quantitatively assessing the quality of radar QPE in the different experiments [43]. The mean deviation error is defined as follows:

$$
\mathrm{BIAS}=\frac{1}{n} \sum_{i=1}^{n}\left(R_{a}(i)-R_{g}(i)\right),
$$

where $R_{a}(i)$ is the radar QPE of the $i$ th station, $R_{g}(i)$ is the observed precipitation of the $i$ th site, and $n$ is the total number of samples involved in the performance assessment.

The radar QPE error may be positive or negative; therefore, its mean will not reflect the radar QPE performance. To objectively reflect performance, the mean absolute error rate is used and is defined as follows:

$$
\mathrm{RAE}=\frac{\sum_{i=1}^{n}\left|R_{a}(i)-R_{g}(i)\right|}{\sum_{i=1}^{n} R_{g}(i)} \times 100 \% .
$$

In addition, downpour and drizzle may coexist during a precipitation process; as the RAE of downpour is larger than that of drizzle, the root mean square error primarily represents the performance of the downpour component of the rainfall:

$$
\operatorname{RMSE}=\left(\frac{\sum_{i=1}^{n}\left(R_{a}(i)-R_{g}(i)\right)^{2}}{n}\right)^{1 / 2} .
$$

As the above three equations imply, a BIAS closer to 0 corresponds to more similar (in the average) QPE and observed rain types, whereas a smaller RAE corresponds to a higher radar QPE accuracy for the entire precipitation process. Similarly, a smaller RMSE indicates a more accurate radar QPE for the heavy precipitation portion of the process.

\section{Long-Term Data Statistics}

Many previous studies have shown that extreme precipitation is likely to take place in the Yangtze River-Huaihe River valley, the Yangtze River valley, and on the southeast coast of China, with persistent, heavy rainfall events being more abundant in June and July [44-46]. Tropical rain has been found in these regions, although underestimation occurs when conventional QPE is utilized. We evaluated three months of data obtained from the Yangtze RiverHuaihe River valley, in order to assess the degree to which 
TABLE 1: Hefei CINRAD radar parameters.

\begin{tabular}{lccccc}
\hline Wavelength & Beam width & Scan mode & Elevation angle & Bin spacing & Obtained data \\
\hline $10 \mathrm{~cm}$ & $\begin{array}{c}1^{\circ} \text { half-power } \\
\text { beam width }\end{array}$ & $\begin{array}{c}360^{\circ} \text { azimuthal } \\
\text { volume }\end{array}$ & $0.5^{\circ}-19.5^{\circ}$ & $\begin{array}{c}250 \mathrm{~m} \text { for velocity and } \\
\text { spectral width; } 1000 \mathrm{~m} \text { for } \\
\text { reflectivity }\end{array}$ & $\begin{array}{c}\text { Reflectivity, radial velocity, } \\
\text { spectral width }\end{array}$ \\
\hline
\end{tabular}

the proposed identification process improves estimation accuracy when compared with analyses conducted using the default WSR-88D $Z-R$ relationship and convectivestratiform precipitation segmentation rain identification scheme. Doppler radar data for this study were taken from the Hefei Doppler radar $\left(117.258^{\circ} \mathrm{E}, 31.867^{\circ} \mathrm{N}, 165.5 \mathrm{~m}\right)$, a Chinese New Generation Radar S-band radar instrument (CINRAD WSR-98D/SA). The WSR-98D/SA is a $10-\mathrm{cm}$ wavelength Doppler radar with a $1^{\circ}$ half-power beam width. The data obtained consisted of volume scans of radar reflectivity, radial velocity, and spectrum width collected in a polar coordinate system, at increasing elevation angles. During periods of precipitation, the radar operates in a $360^{\circ}$ azimuthal volume scan mode, with the elevation angle increasing from $0.5^{\circ}$ to $19.5^{\circ}$ and the temporal resolution of the data depending on the operational mode of the radar. Bin spacing is $250 \mathrm{~m}$ in the radial direction, with reflectivity values averaged over four bins, to increase the number of independent measurements collected for each recorded value. Accordingly, reflectivity values are recorded at $1-\mathrm{km}$ intervals along the radar beam, whereas velocity parameters are recorded at $250 \mathrm{~m}$ intervals. Each volume scan takes approximately $6 \mathrm{~min}$. The radar parameters are shown in Table 1.

3.1. Data and Domain. The data from the Hefei Doppler radar and gauge of Anhui Province were collected from June to August in 2010 . The horizontal domain $\left(115.758^{\circ} \mathrm{E}-\right.$ $\left.118.758^{\circ} \mathrm{E}, 30.367^{\circ} \mathrm{N}-33.367^{\circ} \mathrm{N}\right)$ in this study was a $300 \times$ $300 \mathrm{~km}$ grid centered at the radar with a $1 \mathrm{~km}$ horizontal resolution (a $301 \times 301$ grid). The vertical domain consisted of 73 layers and had an altitude of $18 \mathrm{~km}$ (0.25-km resolution). The center of the horizontal domain is the site of Hefei radar. The domain is shown in Figure 2.

3.2. Statistical Results for Three Months of Data. To compare the estimates obtained with different schemes, some statistical indicators were obtained for the June-August, 2010, period, and are presented in Table 2. As shown, Experiment II performed consistently better than Experiment I, but Experiment III produced the results closest to the observed precipitation and with the greatest precision. It should be mentioned that there is a significant difference between the observed precipitation and the radar estimated rainfall when the intensity of the observed precipitation is less than $2 \mathrm{~mm} / \mathrm{h}$; therefore, rainfall with intensity below $2 \mathrm{~mm} / \mathrm{h}$ was excluded.

The statistical indicators in Table 2 were obtained from all precipitation types; to further understand the particular effects of tropical rain, the statistical indicators specific of tropical rain events that occurred in the June-August, 2010, period are presented in Table 3. In other words, in contrast

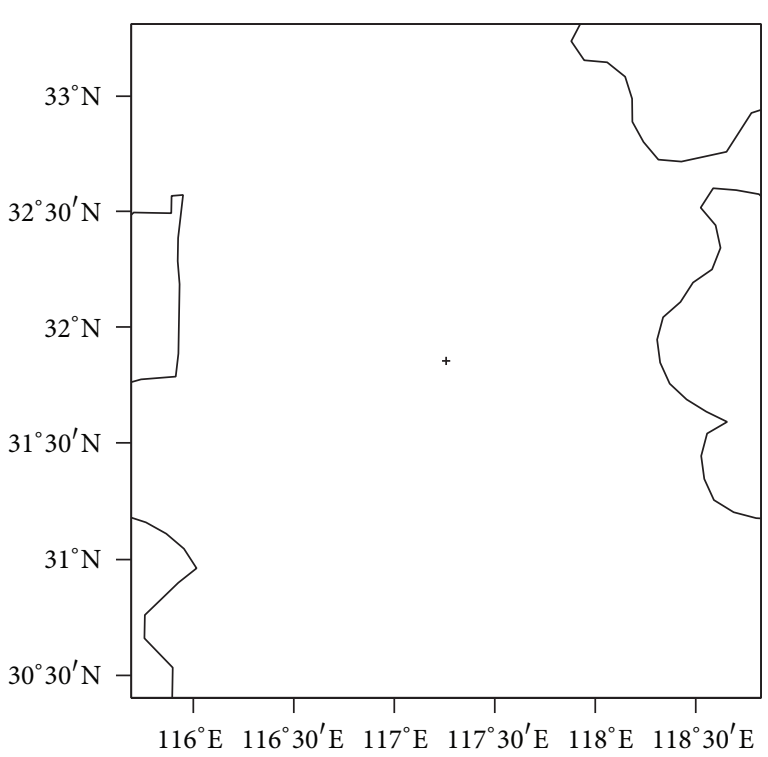

Figure 2: Study domain (the “+” represents the Hefei radar location).

TABLE 2: Error analysis of the June-August, 2010, data.

\begin{tabular}{lccc}
\hline Error & Exp. I & Exp. II & Exp. III \\
\hline BIAS $(\mathrm{mm})$ & -1.299 & -1.124 & -0.219 \\
RAE $(\%)$ & 31.0 & 28.3 & 27.1 \\
RMSE $(\mathrm{mm})$ & 2.191 & 2.100 & 1.877 \\
\hline
\end{tabular}

TABLE 3: Error analysis of stations with tropical rain in the JuneAugust 2010 period.

\begin{tabular}{lccc}
\hline Error & Exp. I & Exp. II & Exp. III \\
\hline BIAS $(\mathrm{mm})$ & -1.912 & -1.791 & 0.041 \\
RAE $(\%)$ & 32.3 & 31.0 & 22.7 \\
RMSE $(\mathrm{mm})$ & 3.354 & 3.314 & 2.327 \\
\hline
\end{tabular}

with Table 2, the statistical indicators in Table 3 do not consider data from grid points not experiencing tropical rainfall. The results in Table 3 match those of Table 2 in that radar QPE is noticeably improved using the FL method proposed here. This improvement becomes even more significant when in the presence of tropical rainfall events.

To further understand the various precipitation events that took place in June-August, 2010, and better describe how QPE is affected under three rainfall conditions (stratiform, convective, and a hybrid precipitation case in which convective and stratiform precipitation are present at the same time), the three-month period was divided into 12 precipitation 


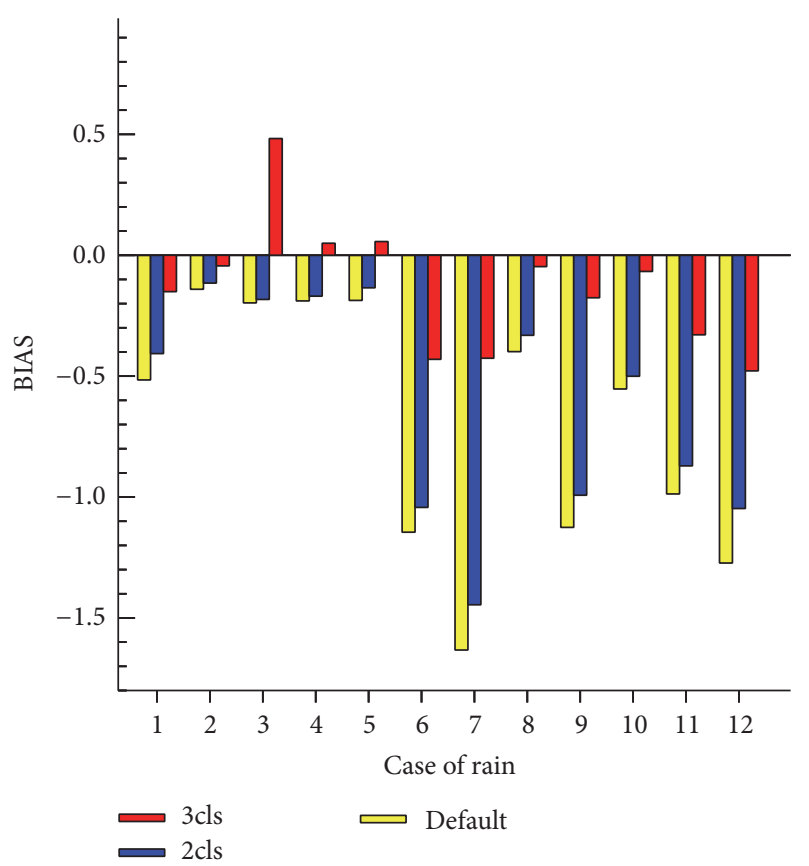

(a)

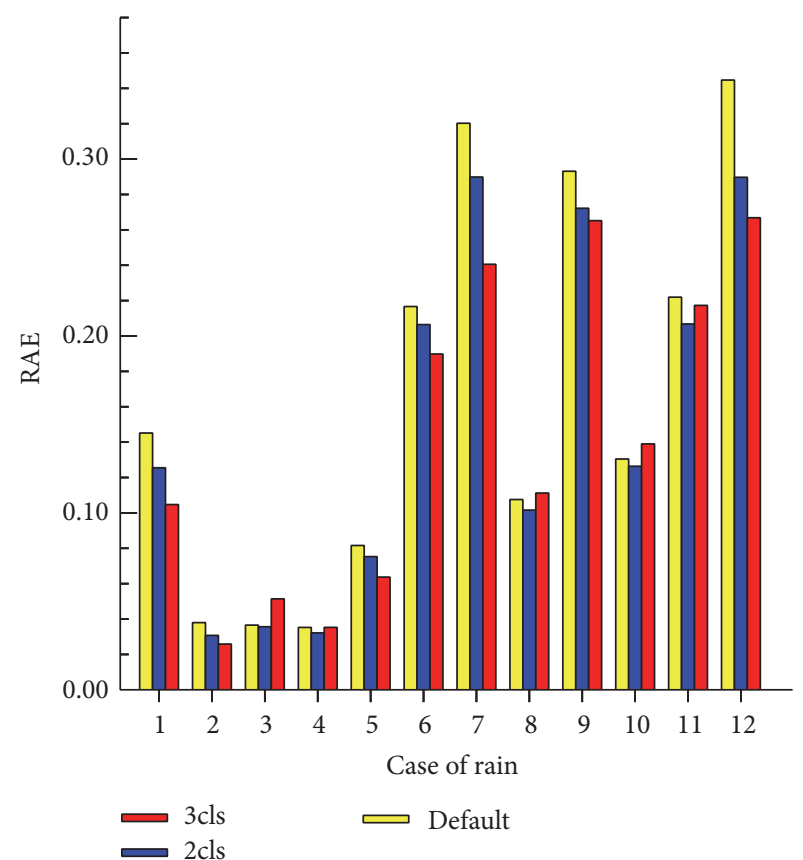

(b)

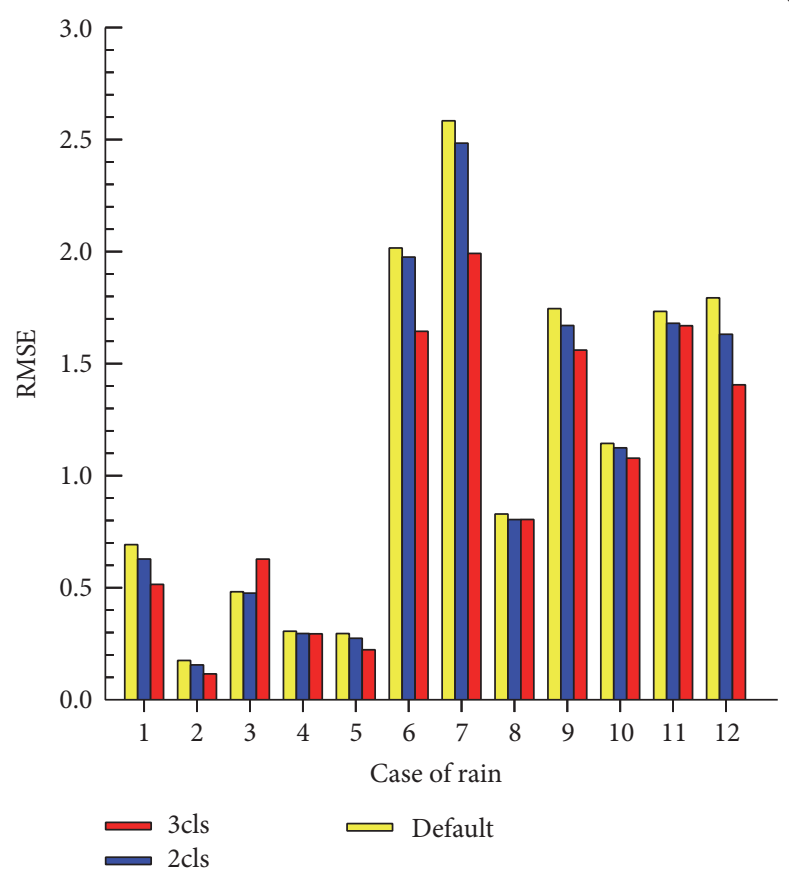

(c)

FIGURE 3: Error statistics considering all stations, for each precipitation process. Label "2cls" represents classification in two precipitation classes (Experiment II), and "3cls" represents classification in three precipitation classes (Experiment III). The units of BIAS and RMSE are $\mathrm{mm}$; RAE is dimensionless.

cases (Table 4). The analysis of the several events is shown in Figure 5, which presents the error curves for each case. As shown, Experiment III consistently produced the lowest error values (with the exception of case 3), particularly in cases 1,6 , and 7 .

Figure 4 shows the same type of information in Figure 3, but this time considering only tropical rainfall events. Thus, as shown, separating precipitation into convective and stratiform using the FL algorithm produces better results than simply using the default $Z-R$ relationship, although separating the precipitation into convective, stratiform, and tropical rain produces results even closer to the observed precipitation, not only for the overall precipitation process but also for the heavy precipitation portion only.

In cases 1, 6, and 7, Experiment III produced the best results; however, its results for case 3 are not very good. 


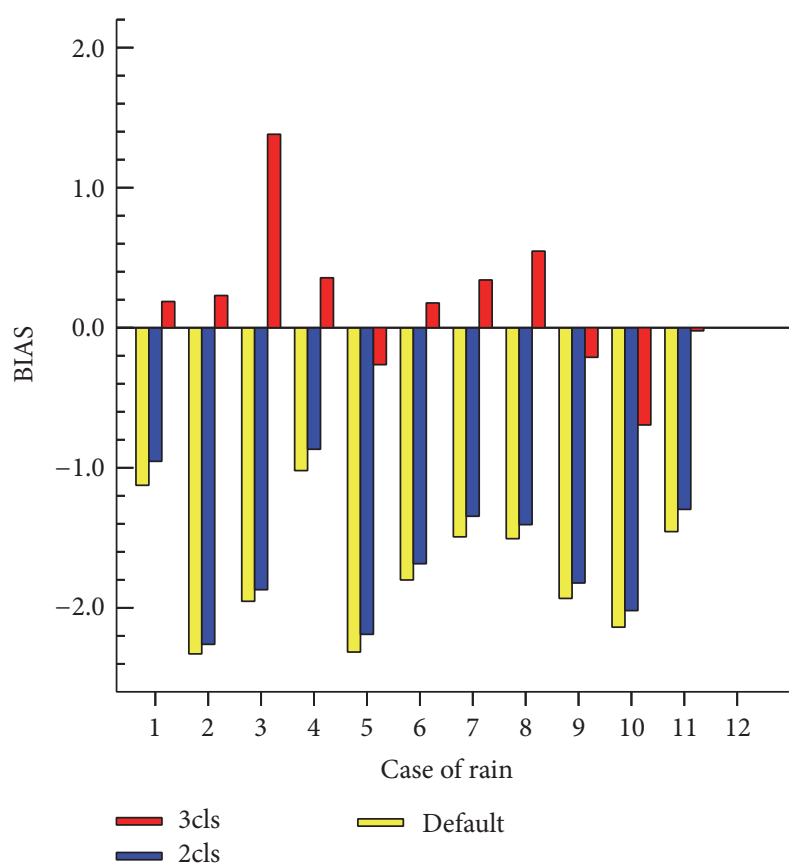

(a)

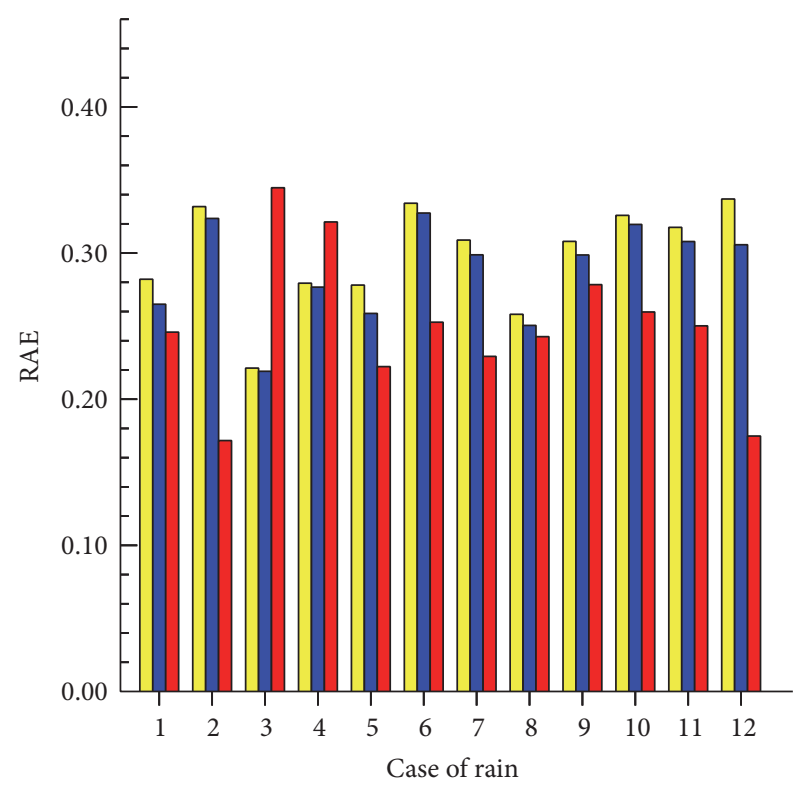

$3 \mathrm{cls}$

ए Default

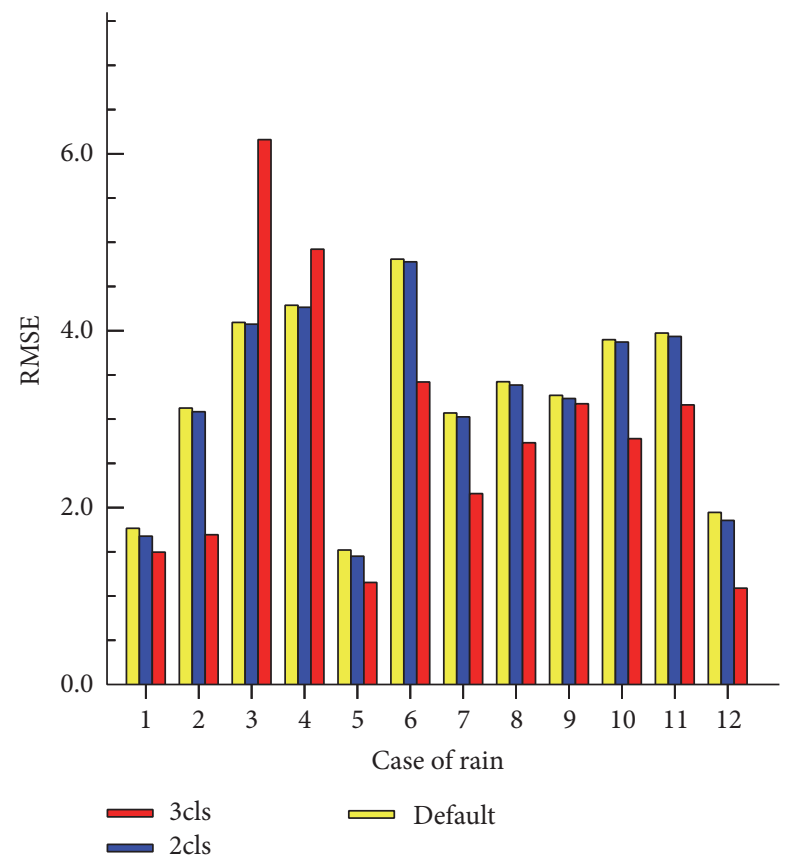

(c)

FIGURE 4: Error statistics considering only tropical rain events. Label "2cls" represents classification in two precipitation classes (Experiment II), and " $3 \mathrm{cls"}$ " represents classification in three precipitation classes (Experiment III). The units of BIAS and RMSE are mm; RAE is dimensionless.

These four cases were therefore selected to further study the different results of the three sets of experiments. The corresponding errors for each station are shown in Figure 5, as a function of time; cases 1, 3, 6, and 7 are represented from the top to the bottom row, respectively, and the BIAS, RAE, and RMSE values are represented in columns, from left to right, respectively. It should be noted that these results are the same ones presented in Figure 3; as shown, in cases 1, 6, and 7, Experiment III not only produced the smallest total errors but also consistently exhibited the lowest errors on an hourly basis. However, the results of Experiment III are not better than those of II or I in case 3. Further analysis revealed that case 3 represents an intermittent rainfall event that was primarily formed by scattered convective cells in 

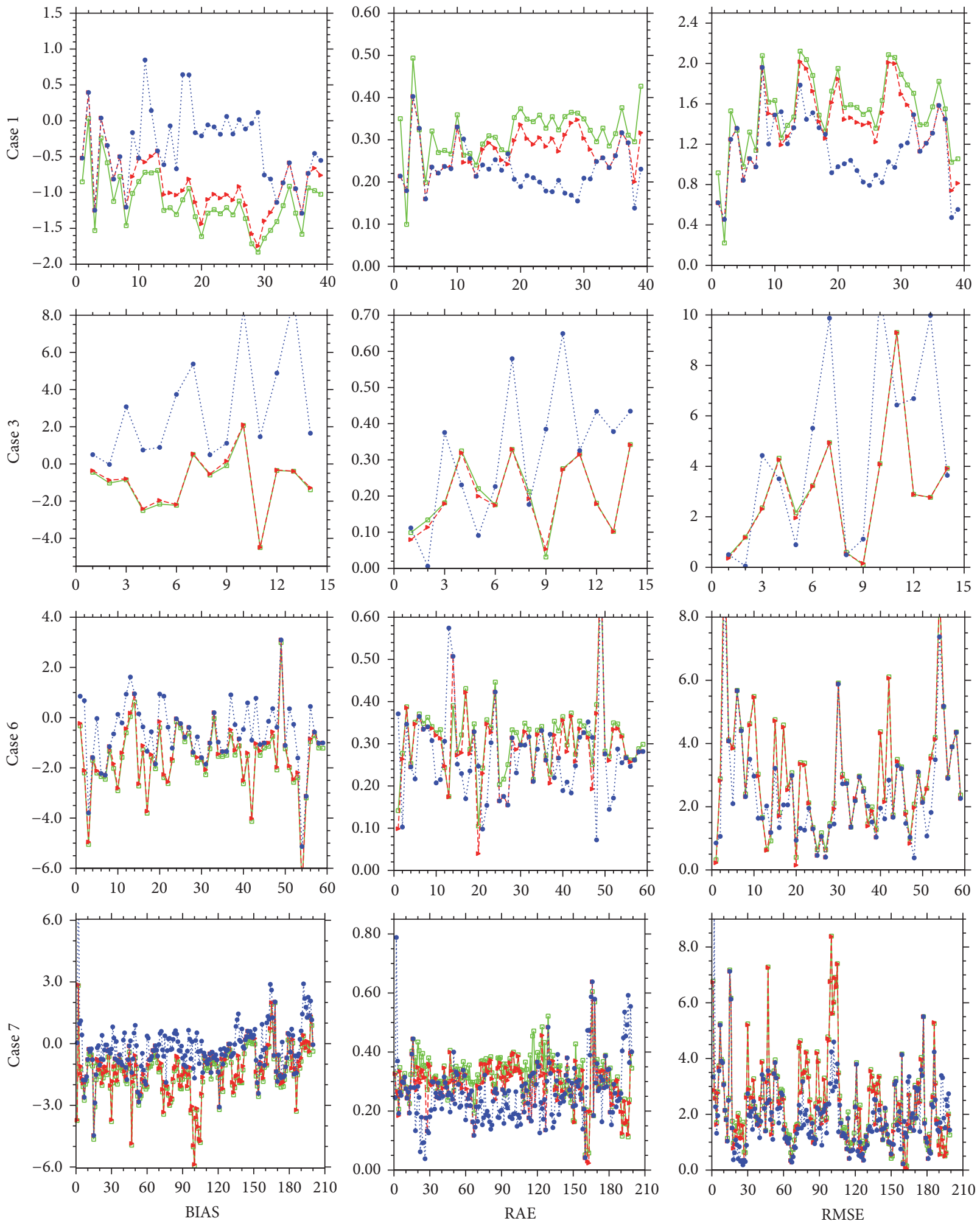

..... $3 \mathrm{cls}$

$\rightarrow$ Default

$\ldots \bullet . .3 \mathrm{cls}$

$\rightarrow$ Default

…3 $3 \mathrm{cls}$

$\rightarrow$ Default

Figure 5: Hourly errors for all stations. Cases 1, 3, 6, and 7. The abscissas represent rainfall duration (unit: h). 


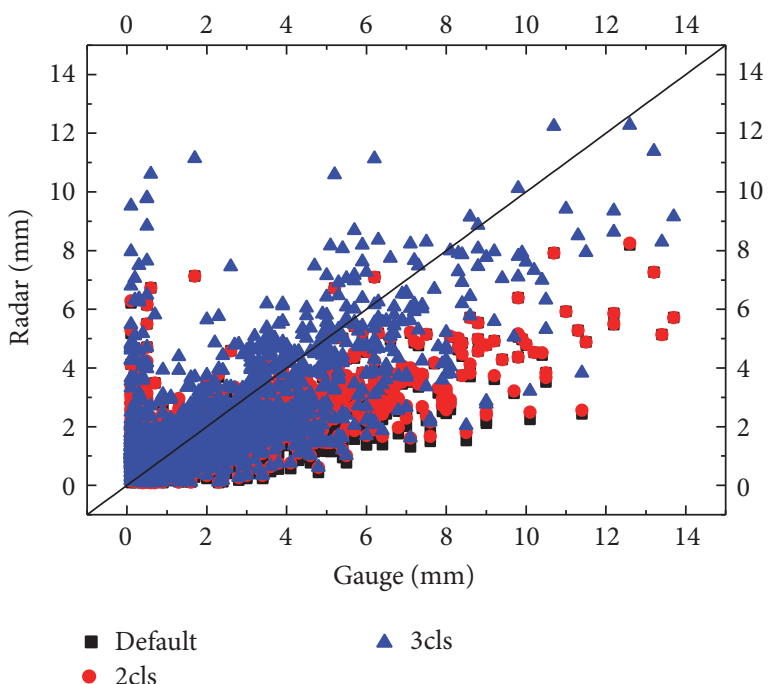

(a)

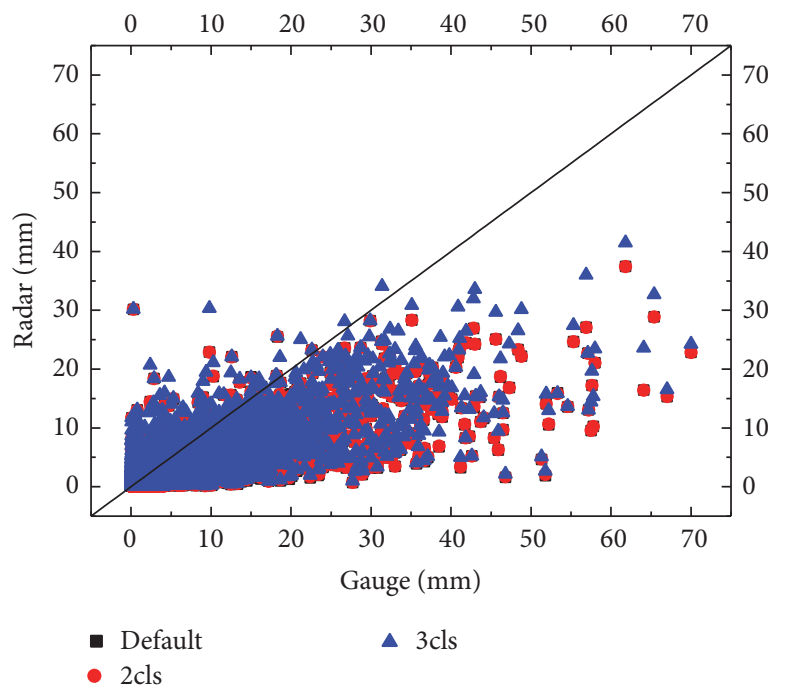

(c)

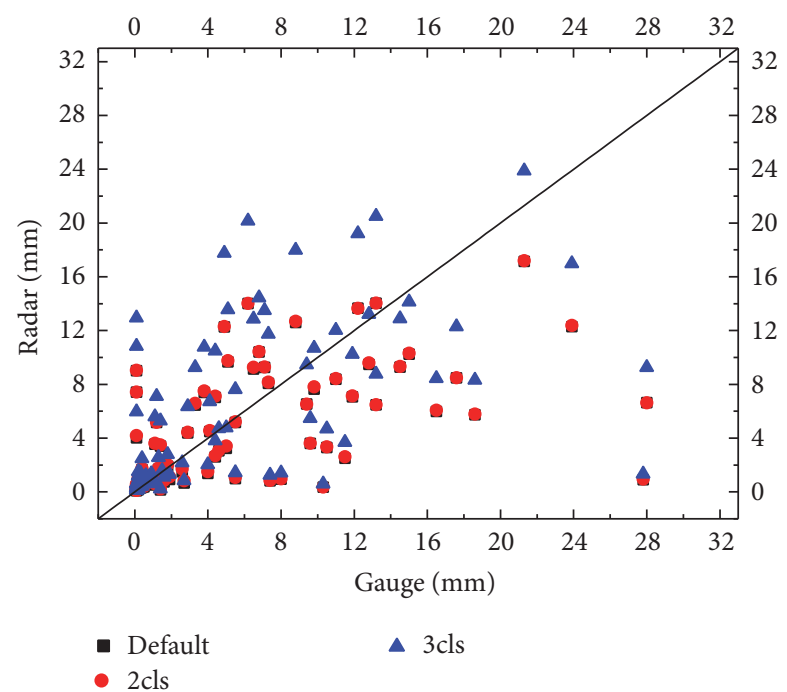

(b)

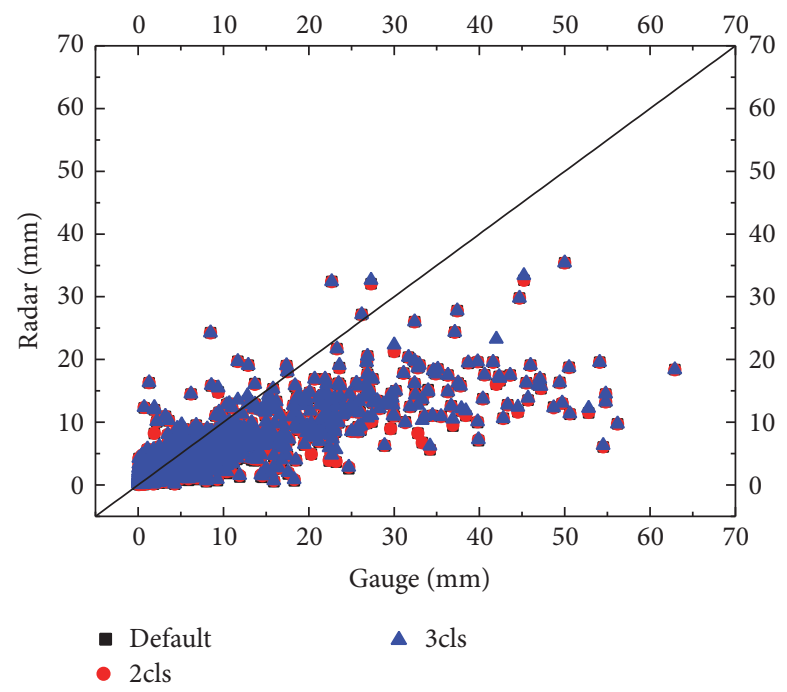

(d)

FiguRE 6: Scatter plot of gauge versus radar-derived 6-h accumulated precipitation estimates (case 3 uses 4-h accumulated precipitation values). (a) Case 1. (b) Case 3. (c) Case 6. (d) Case 7. (The diagonal line represents the ideal line, corresponding to an equality between the radar and gauge estimates.)

which either the precipitation ranges or the rainfall durations were scattered, with each rainfall lasting less than $6 \mathrm{~h}$ and with limited rainfall per hour. The shortcomings in case 3 may also relate to the selected reflectivity-rainfall rate ( $Z$ $R$ ) relationships, as these were obtained by statistics related to seasonal climate and geography. Therefore, further work will have to be performed to better capture local real-time dynamic $Z-R$ relationships in the future.

To better understand the differences between gauge measurements and QPE in terms of the amount of precipitation, scatter plots of gauge versus radar-derived 6-h accumulated precipitation estimates except for case 3, for which 4 -h accumulated precipitation values are used, because in this case the rainfall lasted less than $6 \mathrm{~h}$ are shown in Figure 6. Figure 6(a) shows the results of case 1, in which the strongest precipitation process intensity is $14 \mathrm{~mm} / \mathrm{h}$. It is seen that the precipitation produced by all three experiments corresponds well with observations, in particular the rainfall estimate from Experiment III, and that most of the results approximate the ideal line. In addition, smaller rainfall intensities correspond to bigger errors, particularly at rainfall intensities less than $2 \mathrm{~mm} / \mathrm{h}$. Figure 6 (b) shows the results for case 3 , in which either the precipitation ranges or rainfall durations were scattered. It is clear that the radar-retrieved accumulation precipitation estimations produced in Experiment III mostly improved the problem of underestimation, although overestimation is demonstrated in some stations. Moreover, the results from Experiment II and Experiment I are similar in that convective rainfall precipitation processes are mainly obtained from the FL method classification, a 
TABLE 4: Twelve precipitation events selected for performance evaluation.

\begin{tabular}{lccc}
\hline Event & Precipitation duration & Binary classification & Tropical rain present? \\
\hline 1 & June 07-09 & Stratiform & Yes \\
2 & June 13-14 & Stratiform & Yes \\
3 & June 17-20 & Convective & Yes \\
4 & June 23-24 & Stratiform & Yes \\
5 & June 27-30 & Stratiform & Yes \\
6 & July 02-04 & Convective and stratiform & Yes \\
7 & July 06-19 & Convective and stratiform & Yes \\
8 & July 21-22 & Convective and stratiform & Yes \\
9 & July 24-August 02 & Convective and stratiform & Yes \\
10 & August 04-11 & Convective and stratiform & Yes \\
11 & August 14-20 & Convective and stratiform & Yes \\
12 & August 21-31 & Convective and stratiform & \\
\hline
\end{tabular}

result consistent with Table 4. Figure 6(c) shows the results for case 6 , in which the precipitation area is broader and the strongest intensity is $70 \mathrm{~mm} / \mathrm{h}$. The correspondence between gauge and QPE improves from Experiment I to Experiment III. Figure 6(d) shows the results for case 7, in which the strongest intensity is $60 \mathrm{~mm} / \mathrm{h}$. It is clear that the precipitation for all three experiments corresponds well with observations, especially in the case of Experiment III, which shows a significantly reduced underestimation when compared with Experiments I and II.

\section{Case Studies}

The cases of heavy rainfall events in Hefei (valid at 0800 UTC, July 22, 2009) and Liuzhou (valid at 1300 UTC, June 12, 2008) were analyzed, to test how easily the proposed method could be applied in different places and times. The Liuzhou Doppler $\operatorname{radar}\left(109.456^{\circ} \mathrm{E}, 24.357^{\circ} \mathrm{N}, 346.8 \mathrm{~m}\right)$ is of the same type as the Hefei Doppler radar.

4.1. Heavy Rainfall in Hefei on July 21-23, 2009. Most parts of the Yangtze River-Huaihe River valley and the southern part of the Yangtze River experienced heavy rainfall on July 21-23, 2009 [25], with local downpours of approximately $150 \mathrm{~mm}$ of rain. During this period, there was a wide range of precipitation, including heavy rain that was distributed primarily in the north of Anhui Province, with the precipitation intensity reaching $40 \mathrm{~mm} / \mathrm{h}$.

The distributions of convective and stratiform rainfall based on the classification of the FL algorithm are shown in Figure 7(a), which shows a rainfall process overall dominated by widespread stratiform rainfall embedded with convective rainfall. A stratiform cloud covering a large area appeared throughout the entire precipitation process and was relatively stable. Only a few parts of Hefei could be identified as convective rainfall regions, embedded in a wide region of stratiform rainfall. The convective rainfall regions changed frequently, and their coverage area was very limited. Thus, the range of estimated precipitation is relatively large.

Although the problem of underestimation is mitigated, to some extent, by classifying the precipitation into convective and stratiform precipitation, significant differences between observation and estimation remain; the primary objective of classifying precipitation into convective, stratiform, and tropical precipitation is the improvement of QPE accuracy. Figure 7(b) shows the results obtained for the three types of cloud classification. It is clear that some convective and stratiform precipitation obtained from the FL algorithms are again identified as tropical precipitation, with the corresponding cases redefined as a stratiform, convective, or tropical mixed precipitation.

As can be seen from Figure 7(c), the characteristics of the precipitation event in Hefei on July 21-23, 2009, include the presence of a bright band; it was identified as convective and stratiform mixed precipitation using the FL algorithm, and the VPR slope after bright band correction was found to be negative; in other words, tropical rainfall may have been present in this case.

To demonstrate the differences between the three experiments' results, a scatter plot of gauge versus radar-derived 1-h accumulated precipitation is shown in Figure 7(d). Even though all three experiments produce some degree of underestimation, the correspondence between gauge and radarderived 1-h accumulated precipitation is improved from Experiment I (greatest underestimation) to Experiment III (least underestimation). Thus, Experiment III produces a significantly more accurate estimation of rainfall compared to the other two experiments, particularly when the rainfall intensity is high.

4.2. Liuzhou Rainfall Event during June 11-12, 2008. The primary difference between the Liuzhou precipitation event and the Hefei event is that the Liuzhou precipitation case took place at a different location.

Liuzhou, in the Guangxi Province, received heavy rain at 0800 UTC on June 11, 2008. The 12-h rainfall accumulation from 0400 to 1600 UTC on June 12 reached $233 \mathrm{~mm}$, with heavy rainfall $(307 \mathrm{~mm})$ also occurring in Liujiang County. The water level in Liujiang exceeded the warning level of $2.86 \mathrm{~m}$ until 1900 UTC on June 12. The heavy rainfall caused waterlogging in some areas and a number of road traffic interruptions until June 13, when the rain began to ease. 


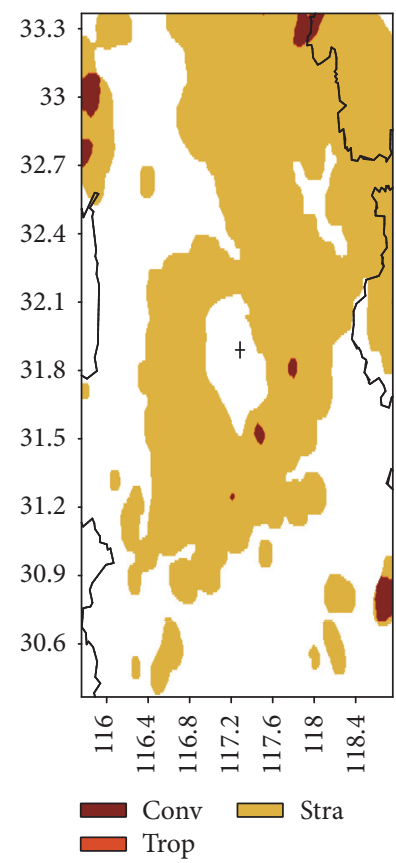

(a)

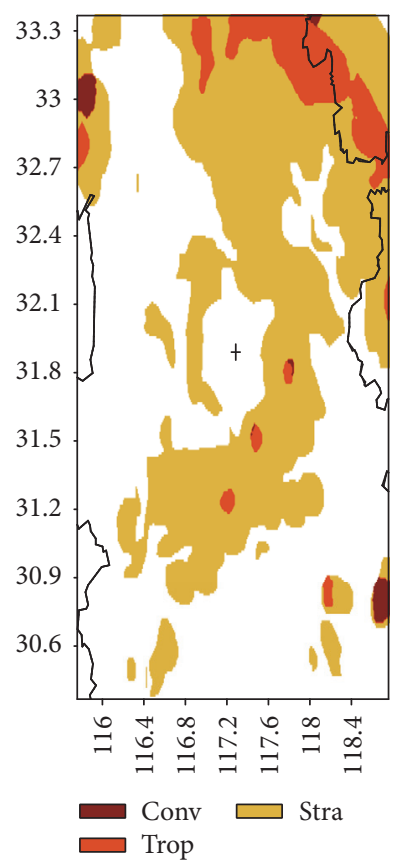

(b)

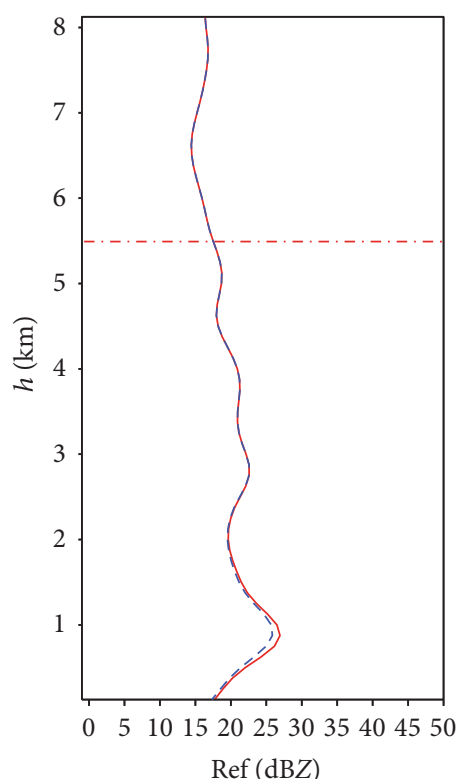

(c)

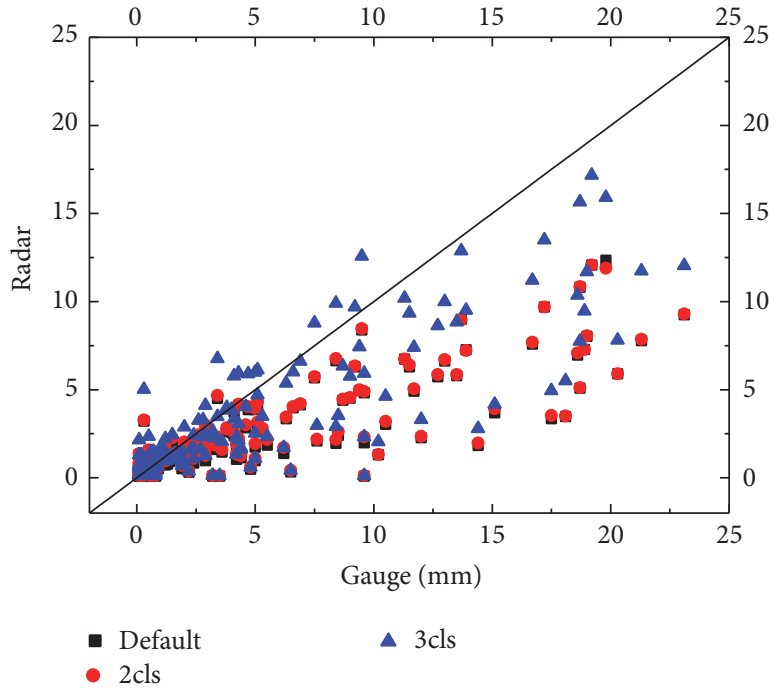

(d)

FIGURE 7: Hefei heavy rain (valid at 0800 UTC, July 22, 2009). (a) Results of the FL algorithm (the abscissas represent longitude, the vertical axis represents latitude, the "+" sign represents the radar location, and the colors of "Conv" and "Stra" represent convective and stratiform rainfall regions, resp.). (b) Distribution of the convective, stratiform, and tropical rainfall. (c) Averaged stratiform VPR (the abscissas represent the value of reflectivity in $\mathrm{dBZ}$, the vertical axis represents the altitude in $\mathrm{km}$, the long dashed line is the $0^{\circ} \mathrm{C}$ isotherm altitude, the red solid line is the VPR before bright band correction, and the blue short dashed line is the VPR after bright band correction). (d) Scatter plot of gauge versus radar-derived 1-h accumulated precipitation (the abscissas represent gauge results in $\mathrm{mm}$, the vertical axis represents radar-derived 1-h accumulated precipitation in $\mathrm{mm}$, and the diagonal line represents the ideal line).

Figure 8 shows an analysis of the heavy rainfall in Liuzhou during June 11-12, 2008, valid at 1300 UTC on June 12. Comparing the 1-h rainfall accumulation from the gauges with the convective and stratiform distribution obtained from the FL algorithm (Figure 8(a)), it is clear that the entire process was based primarily on convective rainfall that did not aggregate but was found in the vicinity of the radar. Heavy rainfall reached $25 \mathrm{~mm} / \mathrm{h}$ just next to the radar.
The distributions of the three types of rainfall are illustrated in Figure 8(b), which shows that the Liuzhou event was a mixed stratiform, convective, and tropical precipitation case. Most of the convective and stratiform precipitation obtained from the FL algorithm is again distinguishable as tropical rain, although there is some convective precipitation near the radar, which recognized the area as being dominated by convective precipitation. 


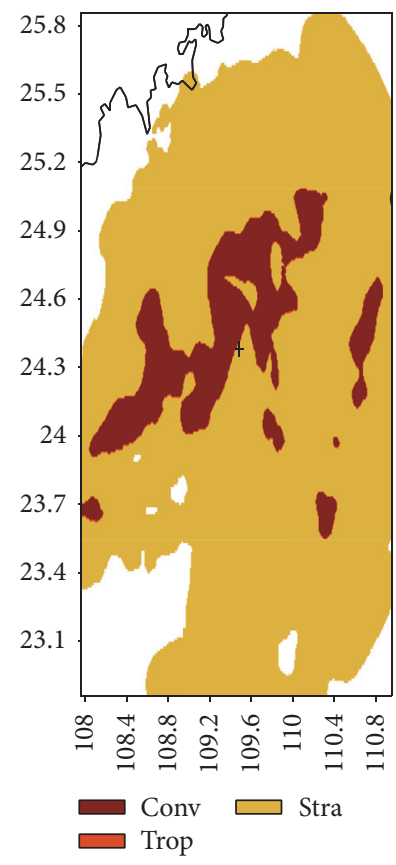

(a)

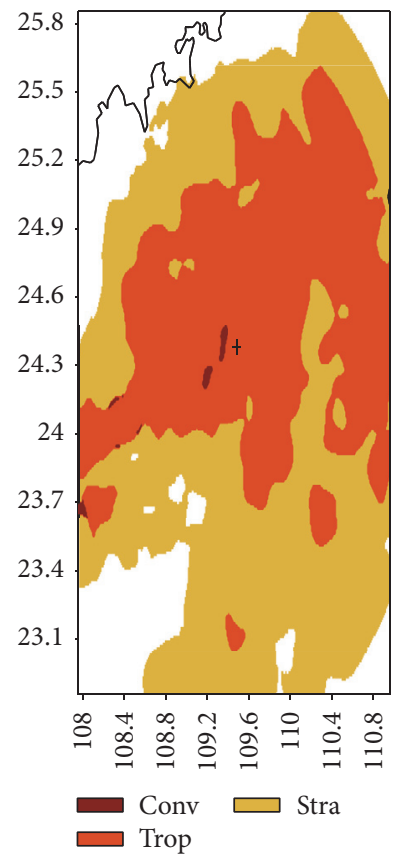

(b)

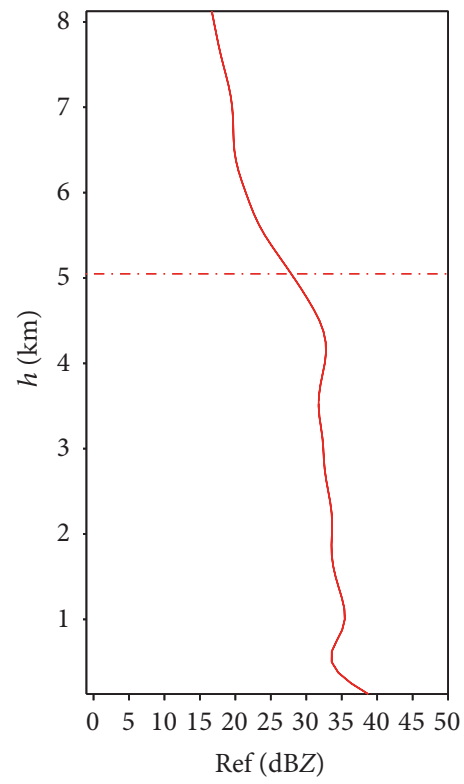

(c)

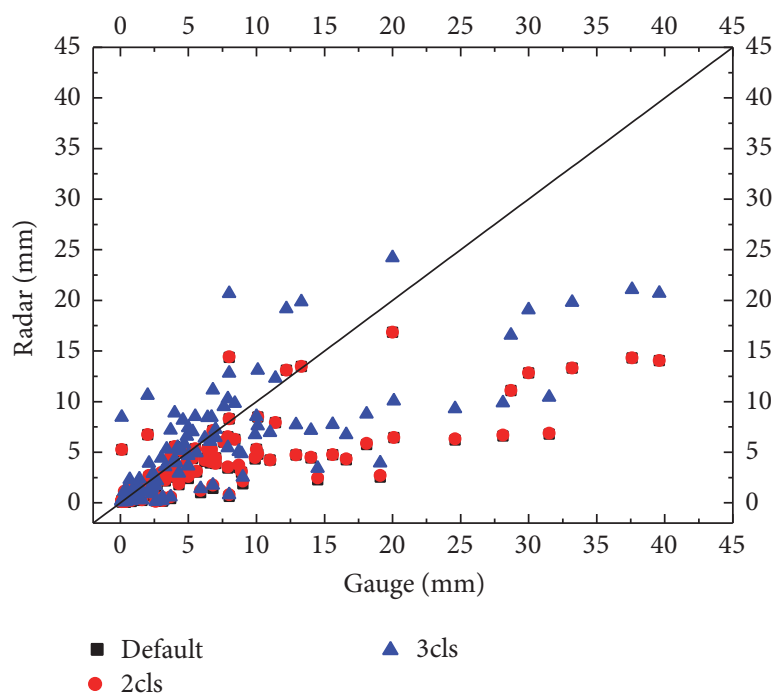

(d)

Figure 8: Heavy rainfall in Liuzhou during June 11-12, 2008, as recorded at (or analyzed for) 1300 UTC on June 12: (a) results of the FL algorithm (the abscissas represent longitude, the vertical axis represents latitude, the "+" sign represents the radar location, and colors of "Conv" and "Stra" represent convective and stratiform rainfall, resp.). (b) Distribution of convective, stratiform, and tropical rainfall. (c) Averaged stratiform VPR (the abscissas represent the value of reflectivity in $\mathrm{dBZ}$, the vertical axis represents the altitude in $\mathrm{km}$, the long dashed line is the $0^{\circ} \mathrm{C}$ isotherm altitude, the red solid line is the VPR before bright band correction. (d) Scatter plot of gauge versus radarderived 1 -h accumulated precipitation (the abscissas represent gauge results in $\mathrm{mm}$, the vertical axis represents radar-derived 1-h accumulated precipitation in $\mathrm{mm}$, and the diagonal line represents the ideal line).

As the VPR shown in Figure 8(c) implies, no bright band is observed for this event. The value of $h_{-} 0^{\circ} \mathrm{C}$ is $5042.6 \mathrm{~m}$, the VPR slope is negative, and tropical precipitation is possibly present.

For comparison between the three experiments, a scatter plot of gauge versus radar-derived $1-h$ accumulated precipitation is provided in Figure 8(d). It is clear that the precipitation of all three experiments corresponds well with observations.
Experiment II performs better than Experiment I, and Experiment III performs the best of all, particularly for large rainfall intensity. Thus, the rainfall estimated by Experiment III is found to correspond most closely to the observed rainfall.

\section{Conclusions}

This paper introduced a method for improving the precision of radar QPE by using an FL algorithm to divide events 
into stratiform and convective precipitation types and then further identifying tropical rain based on the VPR characteristics. First, the proposed method corrects any bright bands that are present. Volume scan reflectivity data from Doppler radar are used to recognize tropical VPRs, using the precipitation classification technique of Xu et al. [33]. Volume scan reflectivity data from Doppler radar are then interpolated to the Cartesian coordinate system over the same latitude and longitude range $\left(0.01^{\circ}\right)$, and the rain is divided into stratiform precipitation and convective precipitation using an FL algorithm [30]. The precipitation is then considered to be tropical rainfall if it has a tropical VPR and the grid at an altitude of $1 \mathrm{~km}$ meets the following criteria: (1) the reflectivity is greater than $25 \mathrm{dBZ}$ and (2) the surface wet bulb temperature is greater than $2^{\circ} \mathrm{C}$. The reflectivity at $1 \mathrm{~km}$ is used to assign an adaptive $Z-R$ relationship. Three sets of experiments were presented in this paper. In Experiment I, for each weather event only the default WSR-88D Z-R relationship $\left(Z=300 R^{1.4}\right)$ was used. In Experiment II, the rain type was identified as convective or stratiform using an FL algorithm; then, the relationships $Z=300 R^{1.4}$ and $Z=$ $200 R^{1.6}$ were applied for convective and stratiform rainfall calculations, respectively. In Experiment III, stratiform and convective rainfall in tropical rainfall events were further divided into stratiform and tropical-stratiform rainfall and convective and tropical-convective rainfall, respectively. The relationships adopted were the same as those used in Experiment II, except that the tropical rainfall relationship was $Z$ $=30.7 R^{1.66}$. A long sequence (three months) of data and two additional study cases were conducted, in order to determine the impact on QPE of the method devised for this study. The conclusions of the study can be summarized as follows:

(1) Although most radar QPEs were lower than the directly observed precipitation for all the rainfall events analyzed in this study, the results of all three experiments corresponded closely to the observed precipitation. Separating the precipitation into convective and stratiform types using the FL algorithm enabled better performances compared to simply using the default $Z-R$ relationship. Separating the precipitation into convective, stratiform, and tropical rain produced results that were the closest to the observed precipitation, not only during the whole precipitation processes but also individually within the heavy precipitation portions of these events.

(2) Given that a large-scale precipitation event usually contains multiple types of precipitation, large estimation errors can be introduced if a single $Z-R$ relationship is used for the entire process. The FL algorithm used here can skillfully separate convective precipitation from stratiform precipitation and thus improve the accuracy of radar QPE to some extent. Nevertheless, the problem of underestimation remains. This study built upon the characteristics of tropical precipitation and the convective, stratiform precipitation classification techniques using an FL algorithm; the resulting method was shown to have improved accuracy, not only during the whole precipitation processes but also individually within the heavy precipitation portions of these events.

(3) The proposed tropical rain identification scheme produced similar results when applied to the cases of heavy rainfall in Hefei (valid at 0800 UTC on July 22, 2009) and in Liuzhou (valid at 1300 UTC on June 12, 2008). In future work, the newly proposed scheme will be further tested, to evaluate its general applicability to different times and locations.

\section{Competing Interests}

The authors declare that there is no conflict of interests regarding the publication of this paper.

\section{Acknowledgments}

This research was supported by the National Science Foundation of China (nos. 41175092 and 41375109).

\section{References}

[1] K. P. Georgakakos, "Covariance propagation and updating in the context of real-time radar data assimilation by quantitative precipitation forecast models," Journal of Hydrology, vol. 239, no. 1-4, pp. 115-129, 2000.

[2] Z. Pu and W.-K. Tao, "Mesoscale assimilation of TMI rainfall data with 4DVAR: sensitivity studies," Journal of the Meteorological Society of Japan, vol. 82, no. 5, pp. 1389-1397, 2004.

[3] C. S. Gardner and W. Yang, "Operational C-band dualpolarization radar QPE for the subtropical complex terrain of Taiwan," Advances in Meteorology, no. 11, pp. 1-15, 2016.

[4] M. Gocic, S. Shamshirband, Z. Razak, D. Petković, S. Ch, and S. Trajkovic, "Long-term precipitation analysis and estimation of precipitation concentration index using three support vector machine method," Advances in Meteorology, vol. 2016, Article ID 7912357, 11 pages, 2016.

[5] J. Kalogiros, M. Anagnostou, F. S. Marzano et al., "Mobile radar network measurements for flood applications during the field Campaign of HydroRad Project," in Advances in Meteorology, Climatology and Atmospheric Physics, pp. 137-143, Springer, 2013.

[6] J. S. Marshall and W. M. K. Palmer, "The distribution of raindrops with size," Journal of the Atmospheric Sciences, vol. 5, no. 4, pp. 165-166, 1948.

[7] D. P. Jorgensen and P. T. Willis, "A Z-R relationship for hurricanes," Journal of Applied Meteorology, vol. 21, no. 3, pp. 356-366, 1982.

[8] P. Tabary, A.-A. Boumahmoud, H. Andrieu et al., "Evaluation of two 'integrated' polarimetric Quantitative Precipitation Estimation (QPE) algorithms at C-band," Journal of Hydrology, vol. 405, no. 3-4, pp. 248-260, 2011.

[9] S. M. Hunter, "WSR-88D radar rainfall estimation: capabilities, limitations and potential improvements," National Weather Digest, vol. 20, no. 4, pp. 26-38, 1996.

[10] C. W. Ulbrich and L. G. Lee, "Rainfall measurement error by WSR-88D radars due to variations in Z-R law parameters and the radar constant," Journal of Atmospheric and Oceanic Technology, vol. 16, no. 8, pp. 1017-1024, 1999. 
[11] B. E. Vieux and P. B. Bedient, "Estimation of rainfall for flood prediction from WSR-88D reflectivity: a case study, 17-18 October 1994," Weather and Forecasting, vol. 13, no. 2, pp. 407415, 1998.

[12] F. Tian, M. Cheng, Y. Zhang et al., "An investigation into the effect of rain gauge density on estimating the areal rainfall using a radar-gauge calibration algorithm," Acta Meteorological Sinica, vol. 68 , no. 5 , pp. 717-730, 2010.

[13] X. Wei, Research on self-adaptive optimized algorithm for radar quantificationally estimating precipitation [Ph.D. dissertation], Nanjing University of Information Science \& Technology, 2015.

[14] Q. Zeng, H. He, Y. Zhang et al., "Parameterizations for the raindrop size distribution and its application in radar rainfall estimation," Meterology and Disaster Reduction Research, vol. 38, no. 4, pp. 46-53, 2015.

[15] E. N. Anagnostou, "A convective/stratiform precipitation classification algorithm for volume scanning weather radar observations," Meteorological Applications, vol. 11, no. 4, pp. 291-300, 2004.

[16] J. Gao and D. J. Stensrud, "Assimilation of reflectivity data in a convective-scale, cycled 3DVAR framework with hydrometeor classification," Journal of the Atmospheric Sciences, vol. 69, no. 3, pp. 1054-1065, 2012.

[17] M. Xue, F. Kong, K. W. Thomas et al., "Prediction of convective storms at convection-resolving $1 \mathrm{~km}$ resolution over continental united states with radar data assimilation: an example case of 26 May 2008 and precipitation forecasts from spring 2009," Advances in Meteorology, vol. 2013, Article ID 259052, 9 pages, 2013.

[18] J. Sun, "Convective-scale assimilation of radar data: progress and challenges," Quarterly Journal of the Royal Meteorological Society, vol. 131, no. 613, pp. 3439-3463, 2006.

[19] Y. Qi, J. Zhang, and P. Zhang, "A real-time automated convective and stratiform precipitation segregation algorithm in native radar coordinates," Quarterly Journal of the Royal Meteorological Society, vol. 139, no. 677, pp. 2233-2240, 2013.

[20] Y. Qi, J. Zhang, Q. Cao, Y. Hong, and X.-M. Hu, "Correction of radar QPE errors for nonuniform VPRs in mesoscale convective systems using TRMM observations," Journal of Hydrometeorology, vol. 14, no. 5, pp. 1672-1682, 2013.

[21] Y. Qi and J. Zhang, "Correction of radar QPE errors associated with low and partially observed brightband layers," Journal of Hydrometeorology, vol. 14, no. 6, pp. 1933-1943, 2013.

[22] Y. Qi, J. Zhang, B. Kaney, C. Langston, and K. Howard, "Improving WSR-88D radar QPE for orographic precipitation using profiler observations," Journal of Hydrometeorology, vol. 15, no. 3, pp. 1135-1151, 2014.

[23] J. Zhang, K. Howard, C. Langston et al., "Multi-Radar MultiSensor (MRMS) quantitative precipitation estimation: initial operating capabilities," Bulletin of the American Meteorological Society, vol. 97, no. 4, pp. 621-638, 2016.

[24] S. Chumchean, A. Seed, and A. Sharma, "An operational approach for classifying storms in real-time radar rainfall estimation," Journal of Hydrology, vol. 363, no. 1-4, pp. 1-17, 2008.

[25] P. P. Mapiam and N. Sriwongsitanon, "Climatological Z-R relationship for radar rainfall estimation in the upper Ping river basin," ScienceAsia, vol. 34, no. 2, pp. 215-222, 2008.

[26] T. N. Rao, D. N. Rao, K. Mohan, and S. Raghavan, "Classification of tropical precipitating systems and associated Z-R, relationships," Journal of Geophysical Research Atmospheres, vol. 106, no. 16, pp. 17699-17711, 2001.
[27] M. I. Biggerstaff and S. A. Listema, "An improved scheme for convective/stratiform echo classification using radar reflectivity," Journal of Applied Meteorology, vol. 39, no. 12, pp. 2129-2150, 2000.

[28] D. D. Churchill and R. A. Houze Jr., "Development and structure of winter monsoon cloud clusters on 10 December 1978," Journal of the Atmospheric Sciences, vol. 41, no. 6, pp. 933960, 1984.

[29] M. Steiner, R. A. Houze, and S. E. Yuter, "Climatological characterization of three-dimensional storm structure from operational radar and rain gauge data," Journal of Applied Meteorology, vol. 34, no. 9, pp. 1978-2007, 1995.

[30] Y. Yang, X. Chen, and Y. Qi, "Classification of convective/stratiform echoes in radar reflectivity observations using a fuzzy logic algorithm," Journal of Geophysical Research Atmospheres, vol. 118, no. 4, pp. 1896-1905, 2013.

[31] L. L. Yang, Y. Yang, Y. C. Qi, X. X. Qiu, and Z. Q. Gong, "A case study of radar-derived quantitative precipitation estimation," Advanced Materials Research, vol. 726-731, pp. 4541-4546, 2013.

[32] B. Wang, J. Zhang, W. Xia et al., "Analysis of radar and gauge rainfall during the warm season in Oklahoma," in Proceedings of the 22nd Conference on Hydrology, New Orleans, La, USA, 2008.

[33] X. Xu, K. Howard, and J. Zhang, "An automated radar technique for the identification of tropical precipitation," Journal of Hydrometeorology, vol. 9, no. 5, pp. 885-902, 2008.

[34] Y. Qi, J. Min, J. Zhang et al., "Study of radar quantitative precipitation estimation in summer of the Yangtze RiverHuaihe River valley," in Proceedings of the 27th Annual Meeting of Chinese Meteorological Society on Prectice of Radar Technology Development and Application, 2010.

[35] L. Zhang, L. Chu, F. Ye et al., "The automatic identification of rainfall type by using radar data," Transactions of Atmospheric Sciences, vol. 35, no. 1, pp. 95-102, 2012.

[36] Q. Cao, Y. Hong, J. J. Gourley et al., "Statistical and physical analysis of the vertical structure of precipitation in the mountainous west region of the united states using $11+$ years of spaceborne observations from TRMM precipitation radar," Journal of Applied Meteorology and Climatology, vol. 52, no. 2, pp. 408-424, 2013.

[37] Q. Cao and Y. Qi, “The variability of vertical structure of precipitation in Huaihe River Basin of China: implications from long-term spaceborne observations with TRMM precipitation radar," Water Resources Research, vol. 50, no. 5, pp. 3690-3705, 2014.

[38] J. Zhang and Y. Qi, "A real-time algorithm for the correction of brightband effects in radar-derived QPE," Journal of Hydrometeorology, vol. 11, no. 5, pp. 1157-1171, 2010.

[39] J. Zhang, C. Langston, and K. Howard, "Brightband identification based on vertical profiles of reflectivity from the WSR-88D," Journal of Atmospheric \& Oceanic Technology, vol. 25, no. 10, pp. 1859-1872, 2008.

[40] L. Tang, J. Zhang, C. Langston, J. Krause, K. Howard, and V. Lakshmanan, "A physically based precipitation-nonprecipitation radar echo classifier using polarimetric and environmental data in a real-time national system," Weather and Forecasting, vol. 29, no. 5, pp. 1106-1119, 2014.

[41] Y. Qi, J. Zhang, P. Zhang, and Q. Cao, "VPR correction of bright band effects in radar QPEs using polarimetric radar observations," Journal of Geophysical Research Atmospheres, vol. 118, no. 9, pp. 3627-3633, 2013. 
[42] Y. Xiao, L. Liu, Z. Li et al., "Automatic recognition and removal of the bright band using radar reflectivity data," Plateau Meteorology, vol. 29, no. 1, pp. 197-205, 2010.

[43] X. Gao, J. Liang, and C. Li, "Radar quantitative precipitation estimation techniques and effect evaluation," Journal of Tropical Meteorology, vol. 28, no. 1, pp. 77-88, 2012.

[44] Y. Tang, J. Gan, L. Zhao, and K. Gao, "On the climatology of persistent heavy rainfall events in China," Advances in Atmospheric Sciences, vol. 23, no. 5, pp. 678-692, 2006.

[45] Q. Zhang, C. Liu, C.-Y. Xu, Y. Xu, and T. Jiang, “Observed trends of annual maximum water level and streamflow during past 130 years in the Yangtze River basin, China," Journal of Hydrology, vol. 324, no. 1-4, pp. 255-265, 2006.

[46] Q. Zhang, C.-Y. Xu, Z. Zhang, Y. D. Chen, C.-L. Liu, and H. Lin, "Spatial and temporal variability of precipitation maxima during 1960-2005 in the Yangtze River basin and possible association with large-scale circulation," Journal of Hydrology, vol. 353, no. 3-4, pp. 215-227, 2008. 

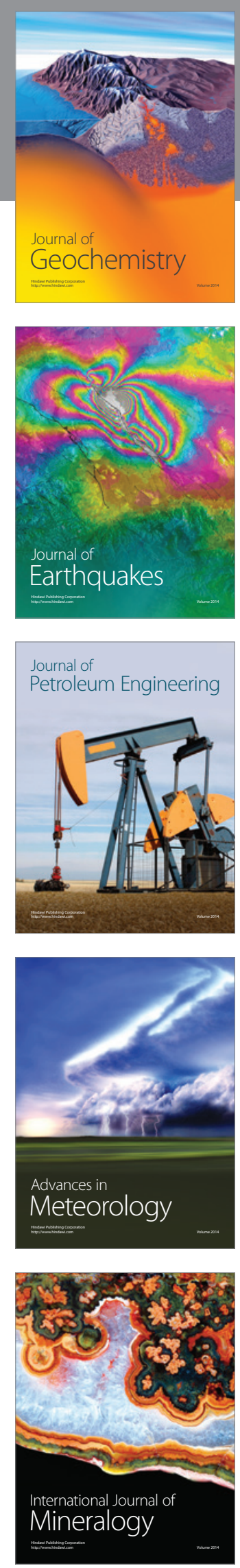
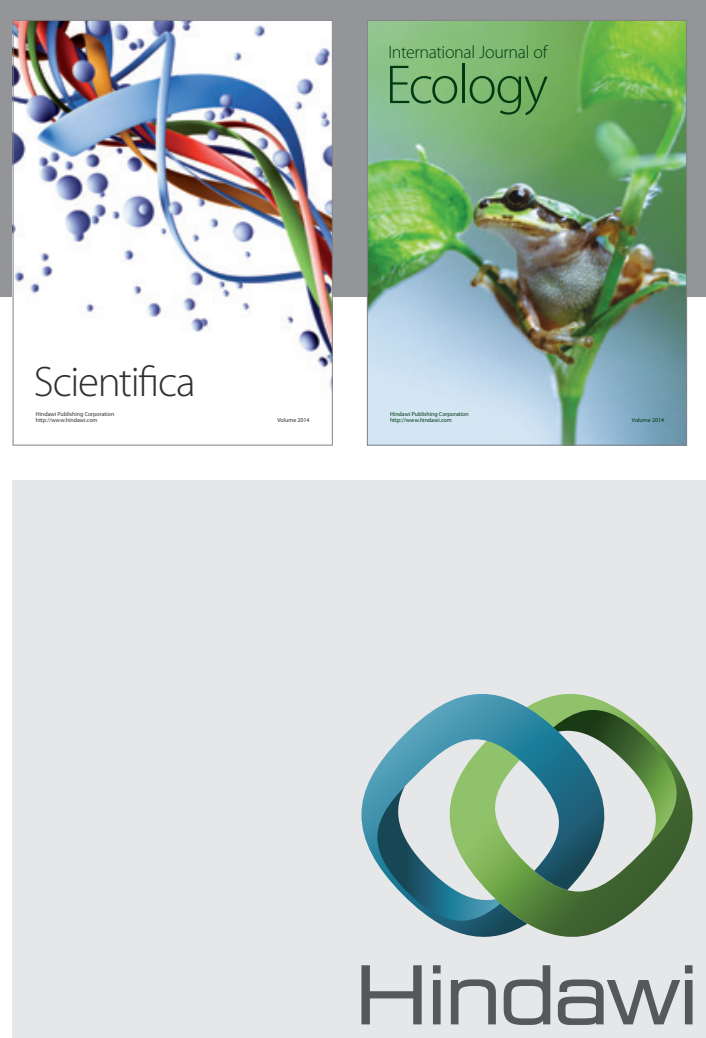

Submit your manuscripts at

http://www.hindawi.com
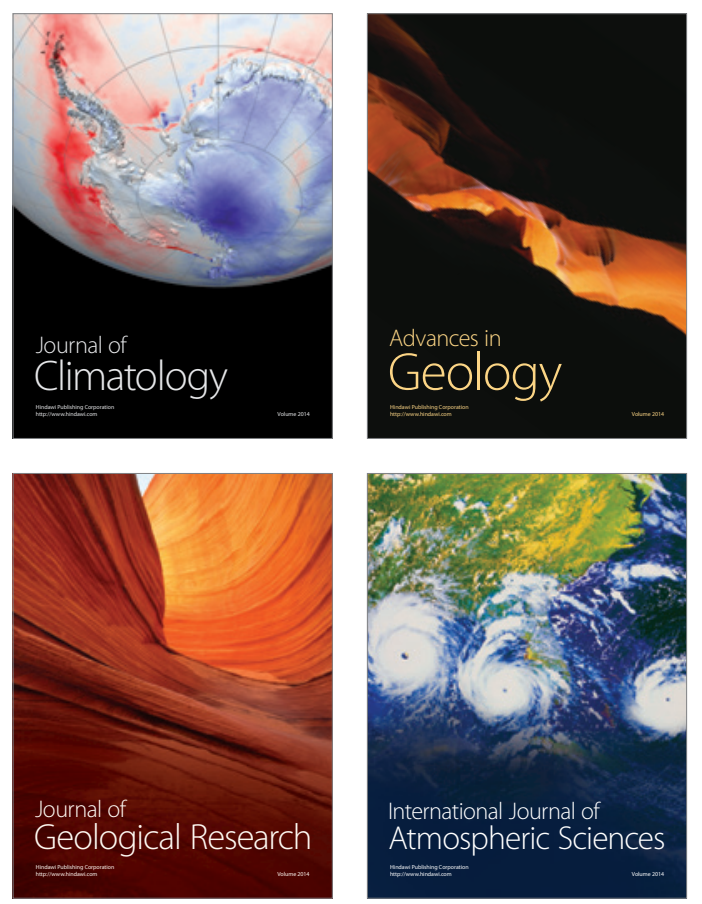

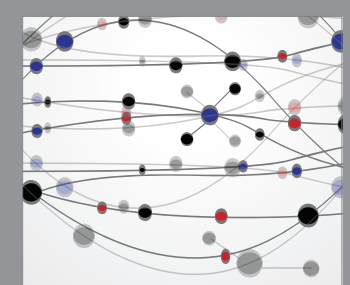

The Scientific

\section{World Journal}
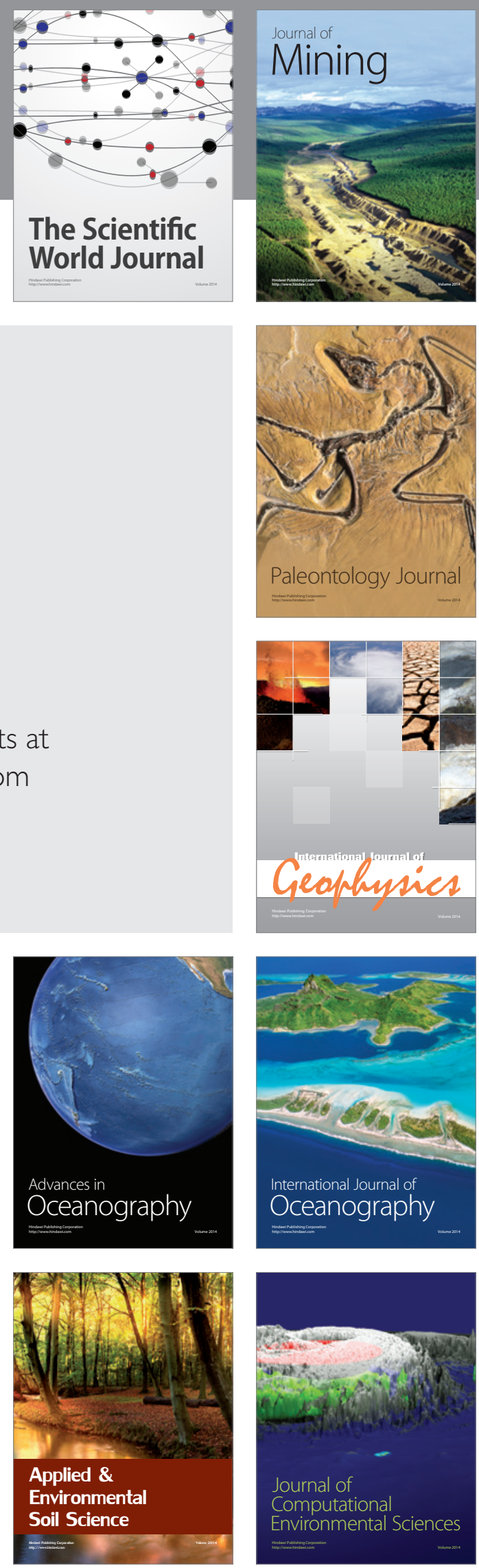